\title{
Follicular growth and atresia in the ovaries of hens (Gallus domesticus) with diminished egg production rates
}

\author{
D. Waddington, M. M. Perry, A. B. Gilbert and M. A. Hardie \\ Agricultural and Food Research Council's Poultry Research Centre, Roslin, Midlothian EH25 9PS, \\ U.K.
}

\begin{abstract}
Summary. Diets containing $3 \cdot 5,1 \cdot 0$ and $0 \cdot 1 \%$ calcium were fed from the age of 42 weeks to individually caged laying hens. Ovaries were examined at 46-49 and 70 weeks of age for changes in the follicular population corresponding to the lowered egg production rates of birds given calcium-deficient diets $(1.0 \%$ and $0.1 \%)$ and older birds given a normal diet $(3 \cdot 5 \%)$.

Growth rates of follicles from $3.5 \mathrm{~mm}$ diameter to ovulation were not changed by the level of dietary calcium in 46-49-week-old birds. The number of atretic small follicles ( $\leqslant 8 \mathrm{~mm}$ diam.) increased in old and calcium-deprived birds, resulting in lower numbers of viable follicles in the intermediate stages of growth (3-8 $\mathrm{mm}$ diam.). There was also an increase in the number of small follicles (1-2 mm diam.) starting to grow in 70-week-old birds which may have partly compensated for the increased loss by atresia. Birds of all ages on all diets were able to produce large follicles up to ovulable size. The main feature of poor laying birds was a reduction in the ovulation rate due to the loss of large follicles ( $>8 \mathrm{~mm}$ diam.) by atresia, an event seen rarely in the birds with good laying performance. As atresia is the normal fate of most of the small follicles, the mechanisms controlling atresia in the small follicles and the large follicles appear to be independent.
\end{abstract}

\section{Introduction}

The functional ovary of the domestic hen at the peak of lay $(>80 \%)$ contains about 60 follicles with diameters between 1 and $8 \mathrm{~mm}$ and a further 6 or so large yolky follicles with diameters up to about $35 \mathrm{~mm}$ (Gilbert, Perry, Waddington \& Hardie, 1983). Growth from $1.5 \mathrm{~mm}$ to ovulation takes about 15 days and appears to be continuous (Perry, Waddington, Gilbert \& Hardie, 1983; Gilbert et al., 1983). However, a normal feature of the hen's ovary is the high incidence of atresia (up to $20 \%$ ) in the smaller follicles $(\leqslant 8 \mathrm{~mm}$ ) (Gilbert et al., 1983), whereas atresia in the large yolky follicles is rare during the laying period, even in species of wild birds (Gilbert, 1979). Observed follicular growth rate varies little, and so egg production may be regulated by the number of follicles initially starting to grow in a given time and the rate of atresia in the small follicles thereafter.

To study these possible relationships required a method by which ovulation could be experimentally controlled and low-calcium diets have been used for this purpose. It is known, for example, that variation in the calcium intake will markedly affect egg production (Evans, Carver \& Drant, 1944; Morris \& Nalbandov, 1958; Hurwitz \& Griminger, 1960; Sullivan \& Kingan, 1962; MacIntyre, Chancey \& Gardiner, 1963; Mehring, 1965; Arends, Miller \& Balloun, 1967). Low levels of calcium in the diet can also be used experimentally to control the period during which eggs are laid (Gilbert, 1969, 1972a, 1973; Blair \& Gilbert, 1973; Gilbert \& Blair, 1975). Furthermore, the number of eggs produced when birds are fed a low-calcium diet is proportional to the amount of calcium in the diet (Gilbert, Peddie, Mitchell \& Teague, 1981a). There may be several possibie explanations for this effect: (a) yolk deposition may be slower, leading to a longer time for follicular 
maturation; (b) there may be a decrease in the number of follicles initially starting growth in a given time; (c) there may be a higher incidence of atresia; and (d) there may be some malfunction of the oviduct resulting in internal laying.

In this report, data on the follicular population of ovaries of birds on normal and restricted calcium diets are presented. Most of the birds were examined when the control birds had high egg production rates. The remainder were examined at a later time when egg production of the control birds had declined naturally.

\section{Materials and Methods}

The 150 hens of a medium-hybrid laying strain (ISA Brown) were housed in individual cages fitted with automatic egg recording equipment. Soft-shelled and grossly damaged eggs were recorded by daily visual observation. These were included in the production figures for the hens because they were derived from normal ovulations. Food and water were provided ad libitum and $14 \mathrm{~h}$ light $(04: 30-18: 30 \mathrm{~h})$ was given each $24 \mathrm{~h}$.

The flock was randomly divided into three groups of 50 hens and each group was fed one of the diets. A basal diet was prepared containing about $0.05 \%$ calcium (Blair \& Gilbert, 1973) and from this the three experimental diets were made by adding the required amount of calcium. The calculated levels were $3.5 \%$ (Group $\mathrm{H}$ ), $1.0 \%$ (Group $\mathrm{M}$ ) and $0.1 \%$ (Group L) respectively. Weekly samples throughout the experiment agreed well with these estimates $(3.34 \pm 0.26,1 \cdot 11 \pm 0.06$ and $0 \cdot 14 \pm 0.03 \%$ ). Birds were allowed 21 days to become accustomed to the experimental diets (Gilbert et al., 1981a). The birds in Group $\mathrm{H}$ served as controls, because a concentration of $3-4 \%$ calcium is recommended for optimum reproductive performance (Poultry Working Group No. 2 (Nutrition) 1981).

At 46 weeks of age, 6 birds selected from each of the 3 groups were fed a single capsule containing Sudan Black B at 09:00 h (Gilbert et al., 1983) and killed by an overdose of pentobarbitone sodium 1 day later. Examination for the number of follicles in each size class and the number of atretic follicles was carried out as described by Gilbert et al. (1983). This procedure was repeated for birds at 47 and 48 weeks of age after intervals of 6 and 3 days, respectively, from the feeding of a dye capsule. At 49 weeks of age 6 birds from each group were killed and their ovaries were also examined. For birds given Sudan Black, the follicles were also scored for the presence or absence of dye.

Identification of atretic follicles in the 1-8 mm size classes has been discussed previously (Gilbert et al., 1983). Atresia in the large (>8 mm) yolky follicles (Gilbert, 1979) was classified as recent (up to about $48 \mathrm{~h}$ from onset) or old. For the most part old atretic follicles were shrunken, most of the yolk had been reabsorbed, and the follicular wall was flabby and discoloured, suggesting an age considerably greater than $48 \mathrm{~h}$.

Ten hens from each of the 3 groups (referred to as older birds) were randomly selected at 46 weeks of age and were given daily a single capsule containing Sudan Black B or Sudan IV (Red) in a non-recurrent sequence for 8 weeks (Gilbert, 1972b) to allow estimates to be made of growth and development times of individual follicles. All eggs were collected, boiled and the yolks halved for examination of the ring pattern.

Thereafter, these hens were maintained on their respective diets until they were about 70 weeks of age. The survivors were then killed and their ovaries examined as for the younger birds aged 4649 weeks.

Statistical analysis. The data consist of follicular counts or measurements of follicular diameter in discrete $1 \mathrm{~mm}$ size classes. The error distributions are often poorly approximated by the Poisson or the Normal distributions and two-way analysis of variance by ranks (Benard \& Van Elteren, 1953) was preferred. There was no test for interaction, but a parametric analysis was used as a guide 
and, when appropriate, this is mentioned in the text. A pooled estimate of the residual mean square (RMS) is given when it is felt that it may be used, with caution, for comparisons. The results from Weeks 4 to 7 of the experimental period were found to be similar and have been pooled for presentation, although not for analysis.

Several of the birds originally selected for the experiments were not included in the analysis of the results because reproductive function was impaired by illness ( 2 younger birds and 1 older bird), the data were incomplete ( 1 younger bird and 4 older birds), or death occurred during the course of the investigation ( 7 older birds). These deaths were not diet-linked.

\section{Results}

\section{Egg production}

The egg production rates are given in Table 1 . They span periods when the younger control birds were just past the peak of lay and when the egg production rates of the older birds had declined. The rates of lay of the birds in Groups $M$ and $L$ declined rapidly and stabilized within 4 weeks of receiving the $\operatorname{diet}(P<0.001$, RMS $=15.7)$.

The decrease in egg production was accompanied by a corresponding reduction in average sequence length $(P<0.001$, RMS $=1.97)$. It was rare for long gaps interspersed by several consecutive days of lay to be observed. In Group L some birds produced 2 or 3 egg sequences at intervals during the 3-week period reported here, some continued to lay sporadically even after 24 weeks on the diet while 3 birds stopped laying within a few weeks of receiving the diet.

The presence of an egg in the oviduct (Table 1) was noted to determine whether oviducal function was affected by calcium depletion. Generally, the groups with the poorer laying records contained fewer birds with an oviducal egg. However, the numbers of younger birds with oviducal eggs in Group $M$ were surprisingly high when compared with their laying records, and it is possible that some eggs were laid with soft-shells and consumed before they could be recorded. There was no evidence that loss of production was caused by internal laying, with the exception of one younger control bird which was not included in Table 1. Therefore, the ovulated ova of the experimental birds traversed the oviduct and were laid normally, although many eggs had defective shells.

Table 1. Average sequence lengths and numbers of laid and oviducal eggs per bird for birds fed on normal (Group H, 3.5\% Ca) and calcium-restricted (Group M, 1.0\% Ca; Group L, 0.1\% Ca) diets

\begin{tabular}{|c|c|c|c|c|c|c|c|c|}
\hline & \multicolumn{3}{|c|}{$\begin{array}{c}\text { Younger birds } \\
(46-49 \text { weeks old })\end{array}$} & \multicolumn{3}{|c|}{$\begin{array}{c}\text { Older birds } \\
\text { (70 weeks old) }\end{array}$} & \multicolumn{2}{|c|}{$\begin{array}{c}\text { Probability for } \\
\text { tests of } \\
\text { differences } \\
\text { between: }\end{array}$} \\
\hline & Group $\mathrm{H}$ & Group M & Group L & Group & H Group M & Group L & Diets & Ages \\
\hline No. of birds & 21 & 23 & 21 & 5 & 7 & 5 & & \\
\hline $\begin{array}{l}\text { Mean sequence length } \\
\text { in final } 22 \text { days }\end{array}$ & $2 \cdot 7$ & $2 \cdot 2$ & 1.4 & 1.4 & $1 \cdot 2$ & $0 \cdot 6$ & $P<0.001$ & $P<0.002$ \\
\hline $\begin{array}{l}\text { No. of eggs laid in } \\
\text { final } 22 \text { days }\end{array}$ & $14 \cdot 3$ & $9 \cdot 4$ & $6 \cdot 2$ & $7 \cdot 8$ & $6 \cdot 0$ & $1 \cdot 2$ & $P<0.001$ & $P<0.001$ \\
\hline $\begin{array}{l}\text { No. of birds with } \\
\text { an oviducal egg }\end{array}$ & 18 & 19 & 10 & 2 & 1 & 0 & & \\
\hline
\end{tabular}

\section{Large follicles ( $>8 \mathrm{~mm}$ diameter)}

The most striking feature of the birds on restricted calcium diets (Groups $M$ and $L$ ) was the occurrence of atresia in the large follicles (Table 2), follicles of the younger hens in Group $\mathrm{H}$ were 
Table 2. Average numbers of viable and atretic large follicles ( $>8 \mathrm{~mm}$ diam.) in the ovaries of birds fed normal (Group H, 3.5\% Ca) and calcium-restricted (Group M, 1.0\% Ca; Group L, 0.1\% Ca) diets

\begin{tabular}{|c|c|c|c|c|c|c|c|c|}
\hline & \multicolumn{3}{|c|}{$\begin{array}{c}\text { Younger birds } \\
\text { (46-49 weeks old) }\end{array}$} & \multicolumn{3}{|c|}{$\begin{array}{l}\text { Older birds } \\
\text { (70 weeks old) }\end{array}$} & \multicolumn{2}{|c|}{$\begin{array}{c}\text { Probability for } \\
\text { tests of } \\
\text { differences } \\
\text { between: }\end{array}$} \\
\hline & Group H & roup $M$ & Group L & Group $\mathbf{H}$ & roup $\mathbf{M}$ & Group L & Diets & Ages \\
\hline No. of birds & 22 & 24 & 23 & 7 & 9 & 6 & & \\
\hline $\begin{array}{l}\text { No. of birds with } \\
\geqslant 1 \text { follicle }\end{array}$ & 22 & 22 & 21 & 5 & 7 & 5 & & \\
\hline $\begin{array}{l}\text { No. of birds with } \\
\geqslant 1 \text { atretic follicle }\end{array}$ & 1 & 9 & 14 & 3 & 7 & 5 & & \\
\hline No. of viable follicles* & $5 \cdot 0$ & $5 \cdot 5$ & $4 \cdot 0$ & $3 \cdot 2$ & $2 \cdot 7$ & $2 \cdot 47$ & & \\
\hline $\begin{array}{l}\text { No. of recent } \\
\text { atretic follicles* }\end{array}$ & $0 \cdot 0$ & $0 \cdot 1$ & 1.0 & $2 \cdot 3$ & 1.6 & $2 \cdot 4\}$ & N.S. & N.S. \\
\hline $\begin{array}{l}\text { No. of old } \\
\text { atretic follicles* }\end{array}$ & $0 \cdot 0$ & 0.8 & $1 \cdot 4$ & $0 \cdot 0$ & $3 \cdot 4$ & $4 \cdot 0$ & & \\
\hline
\end{tabular}

* Average for birds containing at least one large follicle (line 2).

rarely affected. The incidence of atresia was higher in all groups of the older birds. Some birds that had been out of lay for at least 7 days had no large follicles (Table 2).

The average number of large follicles produced by the ovary is the sum of the numbers of viable and recent atretic follicles (Table 2). No differences in age or diet were detectable for these averages. However, the ovaries of some individuals in the experimental groups did contain less than the minimum number of 4 follicles observed in those of the younger Group $H$ birds. These numbered 3 birds in the younger Group L, 3 in the older Group M and 2 in the older Group H birds.

The distribution of viable and atretic follicles varied greatly in birds with low production rates. There were 11 birds that had laid one egg in the preceding week, yet their ovaries contained as many as 4-7 viable follicles. In 6 ovaries there were 5-7 follicles with recent atresia. In 9 other ovaries 4-8 old atretic follicles were present, usually with one or more viable follicles. In birds with a moderate laying record atretic follicles tended to occur singly, at various positions in the hierarchical sequence. By contrast, the F1 follicle always became atretic when LH was administered (Gilbert, Davidson, Hardie \& Wells, 1981b).

These observations indicate that production of large follicles is not necessarily affected in birds with poor laying records. They suggest that the F1 follicle may ovulate and form an egg, whilst the remaining follicles, if not already atretic, may start to become atretic within a very short time. In the following days a new hierarchy of large follicles will be produced and these may ovulate or become atretic.

\section{Small follicles $(1-8 \mathrm{~mm})$}

The average numbers of small follicles are shown in Table 3. The overall pattern was consistent with the earlier results which showed a steady decline in number with increase in size. Exceptionally, in the younger birds the number of 1-2 mm follicles was less than the number in the next, 2-3 mm, category. Viable 1-2 mm follicles increased from 46 to 49 weeks of age $(P<0.001)$. The mean numbers for all diets for these weeks were $6.4,5.9,10.9$ and 14.3. In a previous experiment birds from the same hatch examined at about 30 weeks of age contained an average of 21.8 follicles of 1-2 mm and 13.3 follicles of $2-3 \mathrm{~mm}$ (Gilbert et al., 1983).

The follicles in each category in Table 3 were analysed separately for the effects of diet and age. The approximate parametric analysis suggested that there might be an interaction between diet and time for the 1-2 mm follicles. Overall they appeared to become more numerous with time $(P<$ 
Table 3. Average numbers of viable and atretic small follicles ( $\leqslant 8 \mathrm{~mm}$ diam.) in the ovaries of birds fed normal (Group H, 3.5\% Ca) and calcium-restricted (Group M, 1.0\%; Group L, 0.1\%) diets

\begin{tabular}{|c|c|c|c|c|c|c|c|c|c|}
\hline & \multicolumn{3}{|c|}{$\begin{array}{c}\text { Younger birds } \\
\text { (46-49 weeks old) }\end{array}$} & \multicolumn{3}{|c|}{$\begin{array}{c}\text { Older birds } \\
\text { (70 weeks old })\end{array}$} & \multirow{2}{*}{$\begin{array}{c}\text { Residual } \\
\text { Mean } \\
\text { Square }\end{array}$} & \multicolumn{2}{|c|}{$\begin{array}{c}\text { Probability for } \\
\text { tests of } \\
\text { differences } \\
\text { between: }\end{array}$} \\
\hline & Group $\mathbf{H}$ & Group M & Group L & Group H & I Group M & Group L & & Diets & Ages \\
\hline $\begin{array}{l}\text { No. of birds* } \\
\text { Viable follicles }\end{array}$ & 22 & 22 & 21 & 5 & 7 & 5 & & & \\
\hline 1-2 $\mathrm{mm}$ diam. & $8 \cdot 2$ & $9 \cdot 0$ & $11 \cdot 2$ & $18 \cdot 0$ & 28.7 & $18 \cdot 6$ & 19.7 & N.S. & $P<0.001$ \\
\hline 2-3 $\mathrm{mm}$ diam. & 12.9 & $10 \cdot 6$ & $12 \cdot 5$ & $9 \cdot 5$ & $9 \cdot 0$ & 7.0 & $24 \cdot 2$ & N.S. & N.S. \\
\hline 3-8 $\mathrm{mm}$ diam. & $17 \cdot 2$ & $16 \cdot 4$ & $12 \cdot 9$ & $12 \cdot 0$ & 9.9 & $8 \cdot 0$ & $34 \cdot 1$ & $P<0.05$ & $P<0.002$ \\
\hline $\begin{array}{l}\text { Atretic follicles } \\
1-8 \mathrm{~mm} \text { diam. }\end{array}$ & $14 \cdot 6$ & $20 \cdot 4$ & $28 \cdot 5$ & $20 \cdot 7$ & $32 \cdot 7$ & $30-0$ & $78 \cdot 8$ & $P<0.001$ & $1 P<0.002$ \\
\hline
\end{tabular}

* See Table 2, line 2.

0.001 ). There were fewer 2-3 mm follicles in the older birds of all groups, but there was no statistical support for this observation. There was a decrease in the number of $3-8 \mathrm{~mm}$ follicles with time ( $P$ $<0.002)$ and lower levels of dietary calcium $(P<0.05)$. The average numbers of atretic follicles (Table 3) increased with lower levels of calcium $(P<0.001)$ and with time $(P<0.002)$. The mean numbers of atretic follicles for all diets for Weeks $46-49$ were 18.6, 17.2, 24.0 and 23.9.

Birds with ovaries containing no large follicles had at most an average number of 2-8 mm follicles. One extreme example had the entire follicular population $>1 \mathrm{~mm}$ eliminated by atresia.

\section{Rate of follicular growth and resorption of atretic follicles}

The data on rates of growth and resorption were not as extensive as those for the analysis of follicular numbers. Nevertheless, they did allow some comparisons to be made between the diets. Because the methods for estimating growth rates are unreliable when egg production rates are low and follicle numbers small, no information was collected for older birds.

The time taken for follicles to grow from about $5 \mathrm{~mm}$ to ovulation was estimated from the number of dye rings formed in the yolks of eggs from birds fed daily with capsules of black or red dye. In the yolks of older birds given dye capsules at 47-50 weeks of age, the average number of rings was 9.1 ( 9 birds) for Group H, 9.5 (6 birds) for Group M and 8.8 (6 birds) for Group L. These growth rates appeared to be similar for all groups and agreed with the results obtained in the earlier study (Gilbert et al., 1983).

For the younger birds a second method was used to compare the time taken for follicles to grow from 3.5 to $8 \mathrm{~mm}$. All follicles larger than $3.5 \mathrm{~mm}$ were pulse-labelled by feeding birds a single dye capsule and the ovaries were then examined after 1, 3 and 6 days. As all healthy follicles $>1.5 \mathrm{~mm}$ are growing continuously (Perry et al., 1983), the follicular size corresponding to the boundary between the unlabelled and labelled follicle increases steadily with time. By Day 6 the largest unlabelled follicle in 2 birds was $>8 \mathrm{~mm}$. In general, the average rates of growth were similar for all groups (Table 4) and agreed with the earlier findings. In some ovaries of those in the low calcium group and those examined at 6 days after labelling, the boundary fell within, or next to, a size category that contained no follicles. This may have led to an upward bias for the follicular growth rates of birds in Group L.

The rate of resorption of the small follicles was estimated by counting the labelled and unlabelled atretic follicles. The proportions of atretic follicles that were labelled in birds in Groups $H, M$ and $L$ were, respectively, $0 \cdot 36,0 \cdot 34$ and 0.33 on Day 1 , and $0 \cdot 16,0 \cdot 13$ and $0 \cdot 11$ on Day 3 . On Day 6 only a single dyed atretic follicle was recorded. This result indicates that the increased 
Table 4. The average follicular size ( $\mathrm{mm}$ ) corresponding to the boundary between unlabelled and labelled follicles during the 6 days after the feeding of a single capsule of Sudan Black B for birds (no. in parentheses) fed normal (Group $\mathrm{H}, 3.5 \% \mathrm{Ca}$ ) and calcium-restricted (Group M, 1.0\% Ca; Group L, 0.1\% Ca) diets

\begin{tabular}{lccc}
\hline & \multicolumn{3}{c}{ No. of days after feeding of capsule } \\
\cline { 2 - 4 } & 1 & 3 & 6 \\
\hline Group H & $4.1(6)$ & $5.3(6)$ & $7.1(5)$ \\
Group M & $4.3(6)$ & $5.9(6)$ & $7.5(5)$ \\
Group L & $4.0(3)$ & $5.8(6)$ & $7.9(5)$ \\
\hline
\end{tabular}

Residual Mean Square $=0.8$.

There was no significant difference between diets in boundary size.

number of small atretic follicles in Groups $\mathbf{M}$ and $\mathbf{L}$ cannot be attributed to a slower rate of follicular resorption. No information was available on the resorption of the large follicles, but the process may well follow a similar time-course to that of post-ovulatory follicles and take about 7 days.

\section{Discussion}

There were marked decreases in egg production with age and with lower levels of dietary calcium. Despite this, the ovaries were remarkably similar in each group and were consistent with previous work (Gilbert et al., 1983), except for the high incidence of atresia in birds laying fewer eggs. There was an increased level of atresia in the small follicles $(\leqslant 8 \mathrm{~mm})$ and this resulted in a decreased number of viable follicles in the size range $3-8 \mathrm{~mm}$. Nevertheless, the ovary was still able to produce normal numbers of large follicles up to ovulable size. The most notable feature was atresia of the large yolky follicles.

The increased loss of small follicles by atresia with age may be partly offset by an increased initiation of growth as measured by the number of follicles in the 1-2 mm class. This may also be true for the birds with lower levels of calcium in the diet at any time, but there is no statistical support for this suggestion from these data. Previous work (Gilbert et al., 1983) has shown that for birds younger than those considered here the number of 1-2 mm follicles was about 22 . The only explanation we have for the low numbers of these follicles in the younger birds in the present experiment is that the ambient temperature (mid-summer) was high.

In their work on surgical removal of large follicles in the quail, Kumagai \& Homma (1974) reported an increased rate of growth of small follicles following the loss of larger follicles and they suggested that oestrogens may be involved. Atresia may also be regarded as a loss in this sense because it is likely that the steroidogenic ability of an atretic follicle is greatly reduced ( $\mathrm{J}$. W. Wells, personal communication). Although the present information on growth rates is limited there is no evidence for an altered rate of growth of small or large follicles.

Since atresia is the normal fate of the small follicles, and is the fate of large follicles in adverse conditions only, the mechanisms controlling the maintenance of follicular development appear to be different in the two types. The nature of these mechanisms is uncertain. The gonadotrophins are involved in follicular development and the production of gonadotrophins may be adversely affected by low-calcium diets (Morris \& Nalbandov, 1958; Taylor, Morris \& Hertelendy, 1962; Luck \& Scanes, 1979, 1980). Nevertheless, circulating gonadotrophins are equally available to the two different populations of follicle. Consequently there may be differences in thresholds for the same 
gonadotrophins between the large and small follicles, although whether this reflects receptor numbers or affinity is not known. Alternatively, the specific gonadotrophin responsible for growth may not be the same for each of the follicular types.

Gilbert et al. (1983) suggested that the bird has two primary control mechanisms regulating ovarian function, namely the regulation of the number of follicles initially starting growth and the regulation of the rate of atresia in the small follicles. This experiment shows that under a wide range of conditions the ovary maintains its ability to produce follicles of all sizes. Under adverse conditions it has another way of modifying the ovulation rate by eliminating the large follicles through atresia.

\section{References}

Arends, L.G., Miller, D.L. \& Balloun, S.L. (1967) Calcium requirement of the turkey breeder hen. Poult. Sci. 46, 727-730.

Benard, A. \& Van Elteren, Ph. (1953) A generalization of the method of $\mathrm{m}$ rankings. Proc. K. ned. Acad. Wet. A $15,358-369$.

Blair, R. \& Gilbert, A.B. (1973) The influence of supplemental phosphorus in a low-calcium diet designed to induce a resting phase in laying hens. $\mathrm{Br}$. Poult. Sci. 14, 131-135.

Evans, R.J., Carver, J.S. \& Drant, A.W. (1944) The influence of dietary factors on egg shell quality. II. Calcium. Poult. Sci. 23, 36-42.

Gilbert, A.B. (1969) The effect of a foreign object in the shell gland on egg production of hens on a calciumdeficient diet. Br. Poult. Sci. 10, 83-88.

Gilbert, A.B. (1972a) Role of calcium in regulating reproductive activity in the domestic fowl. J. Reprod. Fert. 29, 150-151.

Gilbert, A.B. (1972b) The activity of the ovary in relation to egg production. In Egg Formation and Production, pp. 3-21. Eds B. M. Freeman \& P. E. Lake. British Poultry Science, Edinburgh.

Gilbert, A.B. (1973) The use of calcium restricted diet to control egg production in the domestic fowl. Proc. 4 th Eur. Poult. Conf., London, pp. 69-76.

Gilbert, A.B. (1979) Female genital organs. In Form and Function in Birds, Vol. 1, pp. 237-360. Eds A. S. King \& J. McLelland. Academic Press, London.

Gilbert, A.B. \& Blair, R. (1975) A comparison of the effects of two low-calcium diets designed to regulate egg production in the domestic fowl. Br. Poult. Sci. 16, $547-552$.

Gilbert, A.B., Peddie, J., Mitchell, G.G. \& Teague, P.W. (1981a) The egg-laying response of the domestic hen to variation in dietary calcium. Br. Poult. Sci. 22, 537-548.

Gilbert, A.B., Davidson, M.F., Hardie, M.A. \& Welis, J.W. (1981b) Induction of atresia in the domestic fowl (Gallus domesticus) by ovine LH. Gen. comp. Endocr. 44, 334-349.

Gilbert, A.B., Perry, M.M., Waddington, D. \& Hardie,
M.A. (1983) Role of atresia in establishing the follicular hierarchy in the ovary of the domestic hen (Gallus domesticus). J. Reprod. Fert. 69, 221-227.

Hurwitz, S. \& Griminger, P. (1960) Observations on the calcium balance of laying hens. J. agric. Sci., Camb. 54, 373-377.

Kumagai, S. \& Homma, K. (1974) High oestrogen production of the medium-sized follicles during follicular growth and ovulation in the laying quail. Endocrinol. japan. 21, 349-354.

Luck, M.R. \& Scanes, C.G. (1979) The relationship between reproductive activity and blood calcium in the calcium-deficient hen. Br. Poult. Sci. 20, 559-564.

Luck, M.R. \& Scanes, C.G. (1980) Ionic and endocrine factors influencing the secretion of luteinizing hormone by chicken anterior pituitary cells in vitro. Gen. comp. Endocr. 41, 260-265.

MacIntyre, T.M., Chancey, H.W.R. \& Gardiner, E.E. (1963) Effect of dietary energy and calcium level on egg production and egg quality. Can.J. Anim. Sci. 43, 337-343.

Mehring, A.L. (1965) Effect of dietary calcium on broilertype laying chickens. Poult. Sci. 44, 240-248.

Morris, T.R. \& Nalbandov, A.V. (1958) The induction of ovulation in starving pullets using mammalian and avian gonadotrophins. Endocrinology 68, 687-697.

Perry, M.M., Waddington, D., Gilbert, A.B. \& Hardie, M.A. (1983) Growth rates of the small yolky follicles in the ovary of the domestic fowl. IRCS Med. Sci.11, 979-980.

Poultry Working Group No. 2 (Nutrition) (1981) Wld's Poult. Sci. J. 37, 127.

Sullivan, T.W. \& Kingan, J.R. (1962) Effect of dietary calcium level, calcium lactate and ascorbic acid on the egg production of S.C. White Leghorn hens. Poult. Sci. 41, 1596-1602.

Taylor, T.G., Morris, T.R. \& Hertelendy, F. (1962) The effect of pituitary hormones on ovulation in calcium deficient pullets. Vet. Rec. 74, 123-125.

Received 9 August 1984 